\title{
REVITALISASI PENDIDIKAN AKHLAK MULIA DALAM PEMBENTUKAN KARAKTER MAHASISWA DI PERGURUAN TINGGI AGAMA ISLAM
}

\author{
Muhamad Tisna Nugraha \\ Fakultas Tarbiyah dan lmu Keguruan (FTIK) \\ Institut Agama Islam Negeri (IAIN) Pontianak \\ E-mail : tisnanugraha2014@yahoo.com
}

\begin{abstract}
The education of akblaq in the Islamic University basically has suited the purpose of national education, to create the potential of students in order to be a great human. Furthermore, as a part of the national education system, the Islamic University has a significant role to actualize the function and goal of the national education system. Due to that reason, the Islamic Education curriculum implemented in the Islamic University becomes a compulsory subject of the personality development subjects, especially to create the great humankind (which has al-akblaq al-karimah) based on strong faith and sharia roles.

Moreover, the embed noble character among the students of the Islamic University is important. Besides, the Islamic University is the forefront for the citizen and the other higher education institutions to behave and act in the daily life activities. Therefore, the revived efforts by facilitating and supporting the students in the Islamic University in order the noble character could be realized despite their creativity and intelligence.
\end{abstract}

Keywords: Revitalitation, Noble Character

\section{PENDAHULUAN}

Mutu pendidikan di Indonesia yang ada di Indonesia saat ini cenderung tidak meningkat, cenderung menurun secara kualitas. Salah satu indikator hal tersebut adalah semakin banyaknya lulusan institusi pendidikan yang tidak dapat memiliki kesiapan dalam memasuki dunia kerja sesuai dengan ilmu dan bidang yang ditekuninya. Indikator lain yang lebih penting adalah menurunnya krisis moral para lulusan yang semakin hari semakin serta jauh dari tuntunan nilai-nilai sosial dan agama.

Selain itu, telah terjadi pergeseran pardigma masyarakat dalam memaknai art dari kemajuan, dimana kemajuan diartikan sebagai maju secara matreri, khususnya dalam bidang ekonomi, sains dan teknologi semata. Padahal secara universal justru akhlak merupakan ciri dan cermina dari kepribadian suatu bangsa serta merupakan bentuk kemajuan yang hakiki tegaknya suatu negara maju baik secara moral dan intelektual.

Paradigma ini juga berdampak pada dunia pendidikan yang ada saat ini khususnya di Perguruan Tinggi, sebagaimana dinyatakan oleh Wendi Zarman (2012: 3) :

"Cara pandang ini juga melanda dunia pendidikan tinggi, sehingga diarahkan untuk mencapai targettarget ekonomi. Buktinya nyaris semua iklan perguruan tinggi yang marak menjelang tahun ajaran baru menunjukan pola yang sama, yaitu menjanjikan kemudahan mendapat kerja setelah lulus nanti. Maka wajar saja kandungan kurikulum didominasi oleh program belajar untuk mengembangkan potensi intelektual dan keterampilan mahasiswa. Sementara itu, pendidikan yang membina kepribadian atau karakter malah terabaikan". 
Untuk mengantisipasi berbagai persoalan tersebut, penyelenggaran pendidikan yang ada saat ini perlu direkonstruksi ulang yang dalam hal ini dilakukan revitalisasi agar dapat menghasilkan lulusan yang lebih berkualitas secara moral dan intelektual. Selain itu, pendidikan harus mampu mengemban misi pembentukan kultur akhlak mulia (character building) sehingga peserta didik dan para lulusan dapat berpartisipasi dalam mengisi pembangunan di masa mendatang tanpa mengenyampingkan nilai-nilai moral atau akhlak mulia (al-akblaq al-karimah).

Salah satu dari beberapa upaya yang dapat ditempuh untuk mewujudkan hal tersebut, adalah dengan memulai langkah revitalisasi pada peserta didik dengan dibekali pendidikan khusus yang membawa misi pokok pesan-pesan dan aplikasi akhlak mulia selama duduk dibangku perkuliahan. Hal ini menurut Soedijarto (2008: 138) merupakan bagian dari strategi penguatan reinforcement strategy atau dalam bahasa teknis kurikulum disebut sebagai salah satu wujud bidden curriculum.

Melalui penyelnggaran pendidikan seperti ini diharapkan dapat memberi arah kepada para peserta didik setelah menerima berbagai ilmu pengetahuan dasar dan ilmu pengetahuan pada bidang (jurusan) masing-masing sehingga mereka dapat mengamalkan ilmu di tengah-tengah masyarakat dengan tetap berpatokan pada nilai-nilai kebenaran dan kebaikan yang universal tersebut. Karena itulah, eksistensi pendidikan yang bernuansa akhlak mulia menjadi sangat penting di Perguruan Tinggi, tidak hanya untuk membekali para peserta didik dalam hal pengamalan nilai-nilai agama yang dianut, tetapi yang terpenting adalah mengantarkan peserta didik agar menjadi manusia yang berbudi pekerti luhur (berakhlak mulia).

\section{REVITALISASI PENDIDIKAN AKHLAK MULIA}

Istilah revitalisasi dan reformasi dalam dunia pendidikan, masih dianggap sebagai hal yang baru. Apalagi kedua istilah tersebut seringkali digunakan dalam sejumlah konteks yang berbeda. Misalnya, reformasi seringkali dikaitkan dalam konteks politik dan budaya, sedangkan revitalisasi lebih kepada konteks ideologi kehidupan berbangsa dan bernegara, sehingga sampai saat ini belum ada rumusan yang baku serta dapat digunakan memaknai dua istilah tersebut, kecuali dalam bentuk rumusan leksikal saja.

Kata revitalisasi, semakin populer di dunia pendidikan ketika Susilo Bambang Yudhoyono yang saat itu menjabat sebagai Presiden RI, menghadiri peringatan Hari Anak Nasional pada tanggal, 23 Juli 2006 di Taman Mini Indonesia Indah. Beliau telah mengintruksikan kepada Menteri Pendidikan Nasional saat itu agar melakukan reformasi dan revitalisasi pendidikan nasional menjelang peringatan hari kemerdekaan RI ke-61. Dalam pidatonya Susilo Bambang Yudhoyono, menyatakan bahwa:

"Bangsa yang memiliki pendidikan yang jelek, tidak akan maju. Bangsa yang maju adalah bangsa yang produktif, inovatif dan cerdas, disamping mempunyai akhlak dan kepribadian yang baik, sehat jasmani dan rohani, dan rukun satu sama lain.” (Kompas, 24-07-06, dalam Winarno Surakhmad, 2009: 122123).

Implikasi dari intruksi Presiden RI tersebut, kemudian berdampak pula pada revitalisasi pendidikan guru-guru di Indonesia sebagaimana dijelasakan oleh Ahmad Rizali dkk (2009: 25) dengan cara meluncurkan program revitalisasi pendidikan/guru/LPTK yang disebut dengan program guru BERMUTU (Better Education thru Reformed Management of Universal Teacher and Upgrading).

Kebijakan tersebut tidak hanya berdampak pada guru-guru di tingkat sekolah, melainkan juga di level Perguruan Tinggi. Hal ini mengingat Perguruan Tinggi memiliki peran dan kiprah yang signifikan sejak kebangkitan nasionnal pertama sampai pada masa revolusi kemerdekaan. Bahkan 
Wakil Presiden Indonesia pertama, yakni Bung Hatta (dalam H.A.R. Tilaar, 1998: 217), menyatakan bahwa :

"Apabila membentuk manusia susila dan demokratis yang insyaf akan tanggungjawabnya atas kesejahteraan masyarakat nasional dan dunia seluruhnya menjadi tujuan yang terutama daripada Perguruan Tinggi, maka titik berat daripada pendidikannnya terletak pada pembentukan karakter, watak. Memang itulah menurut pendapat saya tujuan daripada universitas atau sekolah tinggi. Ilmu dapat dipelajari oleh segala orang yang cerdas dan tajam otaknya, akan tetapi manusia yang berkarakter tidak diperoleh dengan begitu saja. Pangkal segala pendidikan karakter ialah cinta akan kebenran dan berani mengatakan salah dalam menghadapi sesuatu yang tidak benar".

Terkait dengan penyelenggaran pendidikan Islam di Perguruan Tinggi Agama Islam (PTAI). Said Aqil Siroj (2006: 134) pernah mengajukan suatu gerakan revitalisasi ulama untuk menciptakan umat yang kosmopolit atau khaira umamah. Revitalisasi ini diawali dengan niat yang tulus dan baik, bihusninniyah, untuk menata kembali pemahaman atas tiga aspek utama ajaran Islam, yakni akidah, syariat dan akhlak atau tasawuf. Selain itu, Toto Tasmara (2002: 162) juga menegaskan bentuk revitalisasi sebagimana dimaksud, adalah sebagai berikut :

"Revitalisasi (pembaharuan) itu terkait dengan makna tauhid laa ilaaha illalah. Dia tidak mungkin menjadi budak dari kemalasan. Tidak mungkin berdiam diri menerima nasib tanpa ikhtiar, karena Allah telah memberikan begitu banyak kesempatan dan kenikmatan yang menunggu tangan-tangan manusia kreatif untuk mengolahnya".

Berbagai upaya merevitalisasi kualitas pendidikan nasional sebenranya masih terus dilakukan. Termasuk dengan peningkatan anggaran pendidikan mulai ditingkat dasar maupun Perguruan Tinggi. Selain itu, pemerintah juga telah melakukan program sertifikasi guru untuk memenuhi sasaran kualitas yang diharapkan. Bahkan yang terbaru ditahun 2013, pemerintah meluncurkan grand desaign Kurikulum 2013, setelah sebelumnya menggunakan Kurikulum Tingkat Satuan Pendidikan (KTSP). Namun berbagai upaya tersebut tidak serta merta mampu meredam ledakan kemajuan teknologi yang diiringi dengan tingkat kriminalitas dan pergesaran nilai yang terjadi di masyarakat.

Realisasi dari penyelenggaraan pendidikan yang berorientasi pada materi ajar, saat ini menjadi kurang bermakna bagi hidup dan kehidupan warga belajar. Pembelajaran yang mengutamakan penguasaan materi ajar seperti yang selama ini terjadi di Perguruan Tinggi, cenderung mengabaikan nilai-nilai moral dan pengembangan karakter peserta didik. Pembelajaran yang mengabaikan pengembangan karakter telah kehilangan ruh dan esensinya sebagai proses pendidikan yang sesungguhnya, yakni sebuah proses untuk mencerdaskan kehidupan berbangsa dan bernegara bagi masyarakat agar menjadi bangsa yang lebih bermartabat. serta memiliki kearifan dan keterampilan sosial sebagai warga negara yang sadar akan jati dirinya sebagai suatu bangsa.

Dari penjelasan tersebut, tak heran jika Herri Susanto (2014: 17) mendefinisikan karakter adalah sebagai berikut:

"Karekter atau dengan kata lain soft skills yaitu tingkah laku pribadi dan antar pribadi yang mengembangkan dan memaksimalkan performa manusia terhadap lingkungannya, misalnya kemampuan memimpin, berinisiatif, kerja tim, memutuskan, negoisasi dan lainnya”. 
Lebih lanjut, pendidikan karakter pada Perguruan Tinggi sebagaimana telah diamanatkan oleh Undang-Undang No 12 tahun 2012 bahwa tujuan pendidikan tinggi yaitu menjadi manusia yang beriman dan bertakwa kepada Tuhan Yang Maha Esa dan berakhlak mulia, sehat, berilmu, cakap, kreatif, mandiri, terampil, kompeten dan berbudaya untuk kepentingan bangsa. Hal ini kemudian dilanjutkan dengan sosialisai yang dilakukan DIKTI pada bulan Juli tahun 2012 sebagai upaya mewujudkan lulusan Perguruan Tinggi yang berkualitas.

Pentingnya prilaku mulia juga dijelaskan oleh A. Rifqi Amin (2014: 107) yang menyatakan bahwa :

"Perilaku mulia merupakan salah satu aspek yang harus dikuasai oleh mahasiswa Islam, karena akhlak mulia merupakan bentuk pengimplementasian dari ajaran Islam yang telah disampaikan oleh dosen. Dengan kata lain kompetensi akhlak mulia merupakan bentuk aktualisasi mahasiswa, sehingga diharapkan tujuan perkuliahan Pendidikan Agama Islam (PAI) tidak hanya terhenti pada penguasaan konsep saja".

Selanjutnya, adapun nilai-nilai pokok yang terkandung dalam akhlak mulia yang terdapat dalam ayat-ayat al-Quran menurut Marzuki (2010: 123) terdapat dalam ; (QS. al-Maidah [5]: 2), menepati janji (QS. al-Maidah [5]: 1), sabar (QS. al-Baqarah [2]: 45), jujur (QS. al-Baqarah [2]: 177), takut kepada Allah Swt. (QS. al-Baqarah [2]: 189), bersedekah di jalan Allah, berbuat adil, pemaaf (QS. al-Baqarah [2]: 177; QS. al-Mu'minun [23]: 1-11; QS. al-Nur [24]: 37; QS. al-Furqan [25]: 35-37; QS. al-Fath [48]: 39; QS. Ali 'Imran [3]: 134), dan toleran (QS. al-Baqarah [2]: 256; QS. al-Kahfi [18]: 29; QS. Yunus [10]: 99).

Beberapa ayat dalam surah di atas, merupakan ketetapan dan ketentuan yang mewajibkan pada setiap orang Islam untuk melaksanakan nilai akhlak mulia dalam berbagai aktivitas kehidupannya. Nilai-nilai itu sebenarnya tidak hanya bisa dilakukan oleh seorang Muslim saja, tetapi siapa pun dapat melakukannya. Itulah nilai-nilai akhlak mulia yang universal yang harus diwujudkan dalam kehidupan manusia khususnya di PTAI.

Selain itu, jika akhlak mulia pada ayat di atas kemudian dikaitkan dengan karakter yang terdapat pada manusia Indonesia, maka akan diperoleh rumusan sebagai berikut :

SINTESIS KARAKTER MANUSIA INDONESIA

\begin{tabular}{|c|c|c|c|c|}
\hline \multirow{2}{*}{ Karkter Qur'anik } & \multicolumn{3}{c|}{ BERIMAN } & \multicolumn{2}{c|}{ BERILMU } \\
\hline Karakter Profentik & Shiddiq & Amanah & Tabligh & Fathonah \\
\hline \multirow{2}{*}{$\begin{array}{c}\text { Delapan Belas } \\
\text { Karakter Manusia } \\
\text { Indonesia }\end{array}$} & Religius & Kerja Keras & Komunikatif & $\begin{array}{c}\text { Rasa Ingin } \\
\text { Tahu }\end{array}$ \\
\cline { 2 - 5 } & Kejujuran & $\begin{array}{c}\text { Tanggung } \\
\text { Jawab }\end{array}$ & $\begin{array}{c}\text { Semangat } \\
\text { Kebangsaan }\end{array}$ & $\begin{array}{c}\text { Gemar } \\
\text { Membaca }\end{array}$ \\
\cline { 2 - 5 } & Kemandirian & Kedisiplinan & Peduli Sosial & Kreativitas \\
\cline { 2 - 5 } & Toleransi & Demokratis & $\begin{array}{c}\text { Peduli } \\
\text { Lingkungan }\end{array}$ & $\begin{array}{c}\text { Menghargai } \\
\text { Prestasi }\end{array}$ \\
\hline
\end{tabular}




\begin{tabular}{|l|c|l|c|c|}
\hline & Cinta Damai & & $\begin{array}{c}\text { Cinta Tanah } \\
\text { Air }\end{array}$ & \\
\hline
\end{tabular}

Sumber: Alivermana Wiguna (2014: 170)

Dari berbagai penjelasan di atas, jelaslah bahwa revitalisasi pendidikan agama Islam di perguruan tinggi hendaknya membawa misi pokok akan terwujudnya manusia (peserta didik serta lulusan) yang memiliki akhlak mulia serta mampu mengamalkan ilmu dan keterampilan yang digelutinya dalam bentuk sikap dan perilaku tanpa meninggalkan nilai-nilai akhlak mulia tersebut, dengan demikian, materi pendidikan agama Islam di PTAI adalah sebagai salah satu mata kuliah Pendidikan Agama dapat mengikuti perkembangan dan tuntutan zaman sehingga mampu mengemban fungsi dan tujuan pendidikan nasional seperti yang ditegaskan di atas.

\title{
PENDIDIKAN AKHLAK MULIA DI PTAI DALAM MEMBENTUK KARAKTER MAHASISWA
}

Krisis akhlak dan moral yang terjadi belakangan ini di Indonesia, mengingatkan kembali pada sebuah kritik sosial yang pernah disampaikan oleh R.Ng. Ranggawarsita beberapa abad yang lalu melalui tulisannya yang berjudul "Serat Kalatida" (dalam Dhanu Priyo Prabowo, 2003: 94-945), yang salah satu bait isinya adalah sebagai berikut:

\author{
Amanangi jaman edan \\ Ewub aya ing pambudi \\ Melu edan nora taban \\ Yen tan melu anglakoni \\ Boya keduman melik \\ Kaliren wekasanipun \\ Dilalah karsa Allah \\ Begya-begyane kang lali \\ Luwih begya kang eling lawan waspada
}

Artinya:

Menemui jaman edan
Akal budi menjadi serba guna
Ikut edan tidak mampu
Kalau tidak ikut menjalani (edan)
Tidak mendapat yang diingini
Kelaparan akbirnya
Kebetulan menjadi kehendak. Allah
Keberuntungan orang yang lupa
Lebih beruntung orang yang selalu sadar dan waspada

Bait diatas mengambarkan beberapa penggalan pesan dari R.Ng. Ranggawarsita terhadap ramalan sikap manusia ketika memasuki zaman baru yang dikenal dengan istilah "zaman edan". Istilah tersebut semakin populer di kalangan masyarakat karena dianggap merepresentasikan perkembangan 
perilaku dan paradigma berpikir sebagian kalangan yang telah mengalami kemerosotan akhlak, moralitas, dan etika. Bahkan dalam beberapa peristiwa, peraturan hukum yang ada dan telah dibuat secara yuridis, dianggap hanya sebuah permainan bagi kalangan kaum elit serta dapat diperjualbelikan.

Selain berbagai persoalan di atas, Nurul Chomaria (2008: 59-60), juga menjelaskan fakta dari krisis akhlak dan moral dengan banyaknya kasus perkosaan sebagai tindak kejahatan yang paling sering terjadi dalam masyarakat serta menduduki peringkat kedua setelah kasus pembunuhan. Hal ini sebagaimana terlihat pada tabel data sebagai berikut:

\begin{tabular}{|l|c|c|}
\hline \multicolumn{1}{|c|}{ Lembaga } & Tahun & $\begin{array}{c}\text { Jumlah } \\
\text { Kasus }\end{array}$ \\
\hline LBH Asosiasi Perempuan Indonesia & 2002 & 528 \\
\cline { 2 - 3 } Untuk Keadilan & 2003 & 627 \\
\hline \multirow{2}{*}{ Polda Metro Jaya } & 2002 & 107 \\
\cline { 2 - 3 } & 2003 & 134 \\
\hline Jaringan Relawan Independen & $2002-2004$ & 93 \\
\hline
\end{tabular}

Sumber : Nurul Chomaria (2008: 59-60)

Lebih lanjut, menurun Anton Tabah (dalam Nurul Chomaria, 2008: 61), dalam delapan tahun terakhir, telah terjadi 13.175 kasus perkosaan diseluruh penjuru tanah air. Artinya jika dihitung secara matematis, rata-rata setiap tahun d Indonesia, telah terjadi 1.650 kasus perkosaan, atau tidak kurang dari 5 orang wanita telah menjadi korban per-hari, atau jika dihitung ke dalam jam pada setiap 5 jam ada 1 wanita telah menjadi menjadi korban perkosaan.

Melihat realitas kehidupan masyarakat yang demikian, terlontar suatu gagasan dan pemikiran untuk menghidupkan kembali pendidikan budi pekerti atau atau yang dalam hal ini dikenal dengan pendidikan akhlak mulia (al-akblaq al-karimab) di dalam membentuk karakter peserta didik yang dalam hal ini mahasiswa di Perguruan Tinggi Agama Islam (PTAI).

Upaya memperbaiki kemerosotan akhlak, moral dan etika melalui penyelenggaraan pendidikan yang berlangsung di perguruan tinggi saat ini, dipandang sebagai suatu hal yang sangat relevan jika melihat justifikasi bahwa di perguruan tinggi hanya menuntut mahasiswa untuk menyelesaikan Satuan Kredit Semester (SKS) semata, sehingga hal ini dianggap belum mampu membangun interaksi yang paradigmatik pendidikan berbasis masyarakat. Akibatnya pendidikan yang ada menjadi kurang bermakna bagi kehidupan mahasiswa setelah menyelesaikan pendidikan formal. Untuk itulah melalui revitalisai pendidikan akhlak mulia dalam pembentukan karakter mahasiswa, akan terwujud mahasiswa yang cerdas dengan intelektual dan kaya dengan moral.

Kekuatan akhlak mulia adalah kekuatan yang teramat penting dan luar biasa untuk dapat menjadi suatu daya tarik untuk memikat banyak manusia di dalam memahami Islam. Selain itu, akhlak mulia adalah sesuatu yang paling berat timbangannya dibandingkan dengan beberapa amalan lainnya. Hal ini sebagaimana dijelaskan dalam sebuah riwayat sebagai berikut:

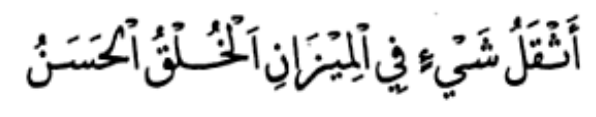

Artinya :

"Sesuatu yang paling berat dalam timbangan adalah akhlak mulia". 
Selain itu, menurut Al-Wasithi dalam Majdi Sayyid Ibrahim (2007: 248) menyatakan bahwa sebagian ulama mengatakan, "Akhlak mulia adalah menahan marah karena Allah; manampakan kegembiraan, kecuali terhadap ahli bid'ah dan orang zalim; memberi maaf kepada orang-orang yang salah, kecuali apabila bermaksud memberi pelajaran dan menegakkan hukum; serta tidak menganggu setiap Muslim, kecuali apabila bermaksud mengubah kemungkaran dan mengembalikan hak yang dizalimi tanpa melampaui batas. Selain itu, Imam 'Ali r.a. mengatakan, "Akhlak mulia terdapat pada tiga hal: menjauhi hal-hal yang haram, mencari rezeki yang halal, dan memberikan kelapangan kepada keluarga."

Upaya dalam mewujudkan akhlak mulia dalam pelaksanaan kurikulum Pendidikan Agama Islam di PTAI di atas, bukanlah hal yang mudah. Banyak hal yang harus diperhatikan oleh berbagai pihak, mulai dari sisi materi yang akan disampaikan, pengelolaan manajerial, metodologi, sarana dan prasarananya, hingga pada sisi kompetensi Sumber Daya Manusia (SDM) baik dari tenaga dosen dan mahasiswanya. Selain itu, yang tidak kalah penting dalam mewujudkan hal tersebut adalah strategi apa yang akan digunakan.

Made Wane (dalam A. Rifqi Amin, 2014: 109), menyatakan bahwa fokus dalam penitiktekanan strategi pembelajaran akhlak mulia ini terletak pada 'cara", yaitu cara-cara yang berbeda di bawah kondisi pembelajaran yang berbeda pula. Adapun strategi pembelajaran sebagaimana dimaksud dapat diklasifikasi menjadi tiga, yaitu:

1. Startegi pengorganisasian (organizational strategy), yaitu cara untuk menata isi suatu biang studi, dan kegiatan ini berhubungan dengan tindakan pemilihan isi/materi, penataan isi, pembuatan diagram, format dan semacamnya.

2. Strategi penyampaian (delivery strategy), adalah cara penyampaian pembelajaran pada mahasiswa dalam menerima serta merespon masukan dari mahasiswa.

3. Strategi pengelolaan (management strategy), yakni cara dalam penataan interaksi antara siswa dengan variable strategi pengorganisasian dan strategi penyampaian. Ini berarati starategi pengelolaan berhubungan dengan pemilihan tentang dua strategi tersebut yang mana harus digunakan selama proses pembelajaran berlangsung. Misalnya dilakukan penjadwalan kontrol pembelajaran, pembuatan catatan kemajuan belajar, dan motivasi.

Lebih lanjut, Wangsadinata dan Suprayitno (2008: 310) menambahkan bahwa :

Metodologi pengajaran haruslah disesuaikan dengan sikap, budaya, motivasi, latar belakang, karakter, bakat dan minat peserta didik. Disamping itu terdapat beberapa implikasi praktis untuk cara praktis dan akademis melakukan pendekatan terhadap hubungan antara mengelola penerapan dan pengembangan konsep revitalisasi pendidikan tinggi di masa mendatang, terutama dalam hal meningkatkan mutu dan relevansi pendidikan dengan kebutuhan pembangunan.

Sebagai mata kuliah pengembangan kepribadian (MPK), Pendidikan Agama Islam di PTU memiliki posisi yang strategis, karena aktivitas perkuliahannya tidak hanya berorientasi pada pengembangan intelektualitas dan ketrampilan mahasiswa, tetapi juga mengasah kalbu (hati) mahasiswa yang menunjang peningkatan iman, takwa, dan akhlaknya. Atas dasar inilah maka visi perkuliahan agama di PTAI secara umum adalah menjadikan ajaran Islam sebagai sumber nilai dan pedoman yang mengantarkan mahasiswa dalam mengembangkan profesi dan kepribadian Islami. Sedangkan misinya adalah terbinanya mahasiswa yang beriman, bertakwa, berilmu, dan berakhlak mulia, serta menjadikan ajaran Islam sebagai landasan berpikir dan berperilaku dalam pengembangan profesi. 
Akhlak mulia merupakan buah yang dihasilkan dari proses penerapan ajaran Islam yang meliputi akidah dan syariah (ibadah dan muamalah). Terwujudnya akhlak mulia di tengah-tengah masyarakat manusia merupakan misi pokok kehadiran Nabi Muhammad saw. di muka bumi ini. Melalui proses panjang dan dengan perjuangan yang tak kenal lelah inilah akhirnya Nabi berhasil mewujudkan akhlak mulia itu di tengah-tengah masyarakatnya dan terus menyebar ke masyarakat yang lebih luas lagi hingga ke berbagai penjuru dunia.

Seiring berjalannya waktu, eksistensi akhlak mulia semakin menurun kualitasnya, dan jika terus dibiarkan, akhlak mulia ini akan terus menurun bahkan menjadi hilang. Jika demikian, bukan tidak mungkin masyarakat manusia akan menjadi masyarakat yang tidak berperadaban lagi (biadab) takubahnya seperti kawanan binatang (QS. al-A'raf [7]: 179). Salah satu cara yang cukup efektif untuk bisa mempertahankan akhlak mulia ini di tengah-tengah masyarakat manusia adalah melalui pendidikan, khususnya pendidikan Islam.

Yang menjadi persoalan penting di sini adalah bagaimana akhlak mulia ini bisa menjadi kultur atau budaya, khususnya bagi mahasiswa. Artinya, kajian tentang akhlak mulia ini penting, tetapi yang lebih penting lagi adalah bagaimana nilai-nilai akhlak mulia bisa teraplikasi dalam kehidupan sehari-hari sehingga menjadi habit atau kebiasaan mahasiswa. Kultur kampus bisa dipahami sebagai tradisi kampus yang tumbuh dan berkembang sesuai dengan spirit dan nilai-nilai yang dianut kampus. Tradisi ini pula akan mewarnai kualitas kehidupan sebuah kampus. Oleh karena itu, nilai-nilai yang ditunjukkan dari yang paling sederhana, misalnya cara mengatur parkir kendaraan dosen, karyawan, mahasiswa, dan tamu, memasang hiasan di dinding-dinding ruangan, sampai persoalan-persoalan teknis lainnya, merupakan bagian integral dari sebuah kultur kampus. Dengan demikian kultur merupakan kebiasaan atau tradisi yang sarat dengan nilai-nilai tertentu yang tumbuh dan berkembang dalam kehidupan sehari-hari dalam berbagai aspek kehidupan. Kultur dapat dibentuk dan dikembangkan oleh siapa pun dan di mana pun. Pembentukan kultur akhlak mulia berarti upaya untuk menumbuh-kembangkan tradisi atau kebiasaan di suatu tempat yang diisi oleh nilai-nilai akhlak mulia.

Salah satu upaya untuk mewujudkan pendidikan seperti di atas, para peserta didik harus dibekali dengan pendidikan khusus yang membawa misi pokok dalam pembinaan akhlak mulia. Pendidikan seperti ini dapat memberi arah kepada para peserta didik setelah menerima berbagai ilmu maupun pengetahuan dalam bidang (jurusan) masingmasing, sehingga peserta didik dapat mengamalkan ilmu di tengah-tengah masyarakat dengan tetap berpatokan pada nilai-nilai kebenaran dan kebaikan yang universal. Karena itulah, eksistensi pendidikan yang bernuansa akhlak mulia seperti Pendidikan Agama, khususnya Pendidikan Agama Islam (PAI), menjadi sangat penting tidak hanya untuk membekali para peserta didik dalam hal pengamalan nilai-nilai agama yang dianut, tetapi yang terpenting adalah mengantarkan peserta didik agar menjadi manusia yang berbudi pekerti luhur (berakhlak mulia). Pembelajaran Pendidikan Agama Islam (PAI) di sekolah maupun perguruan tinggi membawa misi pokok untuk terwujudnya manusia (peserta didik serta lulusan) yang memiliki akhlak mulia serta mampu mengamalkan ilmu dan keterampilan yang digelutinya dalam bentuk sikap dan perilaku tanpa meninggalkan nilai-nilai akhlak mulia tersebut.

\section{PENUTUP}

Islam sangat menekankan bagi pengikutnya untuk melakukan pecaharian ilmu melalui pendidikan, terutama berkaitan dengan akhlak mulia (al-akblaq al-karimab) atau yang lebih populer dengan istilah pendidikan karakter. Dalam upaya mencapai hal tersebut, khususnya di Perguruan Tinggi Agama Islam. Perlu revitalisai yang dilakukan baik dari sisi materi yang disampaikan, 
pengelolaan manajerial, metodologi, sarana dan prasarananya, hingga pada sisi kompetensi Sumber Daya Manusia (SDM) yang berasal dari tenaga dosen dan mahasiswanya.

Sejalan dengan konsep tersebut maka sudah sewajarnya, semua mata pelajaran atau mata kuliah yang diajarkan di PTAI kepada peserta didik yang dalam hal ini adalah mahasiswa, haruslah mengandung muatan pendidikan akhlak mulia. Dari berbagai penjelasan tersebut di atas, selain menekankan pentingnya akhlak mulia pada mahasiswa, para dosen secara bersama-sama harus berusaha untuk meningkatkan kualitas perkuliahan di perguruan tinggi tersebut. Upaya ini misalnya dapat dilakukan dengan jalan: 1) Memperjelas arah penanaman nilai-nilai akhlak mulia di perguruan tinggi dengan berbagai programprogram yang nyata; 2) membangun sarana dan prasarana yang dapat memfasilitasi para mahasiswa untuk berakhlak mulia, misalnya dengan menata ulang waktu perkuliahan agar tidak mengganggu melaksanakan ibadah dan membuat peraturan yang lebih tegas; dan 3) Para dosen, karyawan, dan semua pimpinan perguruan tinggi harus menjadi model atau suri tauladan dalam pembentukan akhlak mulia ini di kampus.

Jika berbagai upaya tersebut bisa direalisasikan, maka upaya penanaman nilai-nilai akhlak mulia di kalangan mahasiswa PTAI akan terealisasi dengan baik, meskipun hal tersebut memerlukan kesabaran, kontinuitas serta tidak dapat terjadi secara instan atau membutuhkan waktu butuh yang lama. Apalagi hal ini berkaitan dengan akhlak manusia yang melakat dalam hati dan sanubarinya.

\section{REFERENSI}

Amin. A. Rifqi. 2014. Sistem Pembelajaran Islam Pada Perguruan Tinggi Umum. Yogyakarta: Deepublish.

Chomaria, Nurul. 2008. Aku Sudah Gede (Ngobrolin Pubertas Buat Remaja Islam). Jawa Tengah: Samudera. Ibrahim. Majdi Sayyid 2007. 50 Nasihat Rasulullab untuk Kaum Wanita. Bandung: PT. Mizan Pustaka.

Tilaar. H.A.R. 1998. Beberapa Agenda Reformasi Pendidikan Nasional dalam Perspektif Abad 21. Magelang: Tera Indonesia.

Khadhar. Lathifah Ibrahim. 2005. Ketika Barat Memfitnah Islam. Jakarta: Gema Insani Press.

Marzuki. Jurnal Cakrawala Pendidikan, Juni 2010, Th. XXIX, NO. 2.

Mulyadi. 1998. Total Quality Management. Yogyakarta: Aditya Media.

Mulyasa. 2011. Manajemen Pendidikan Karakter. Jakarta: PT Bumi Aksara.

Muhaimin. 2003. Arah Baru Pengembangan Pendidikan Islam "Pemberdayaan, Pengembangan Kurikulum Hingga Redefinisi Islamisasi Pengetabuan”. Bandung: Nuansa

Prabowo. Dhanu Priyo. 2003. Pengarub Islam dalam Karya-Karya R.Ng. Ranggawarsita. Yogyakarta: Narasi.

Rizali, Ahmad dkk. 2009. Dari Guru Konvensional Menuju Guru Profesional. Jakarta: PT. Gramedia Widiasarana Indonesia (Grasindo).

Siroj, Said Aqil. 2006. Tasawuf Sebagai Kritik Sosial Mengedepankan Islam sebagai Inspirasi, Bukan Aspirasi. Bandung: PT. Mizan Pustaka. 
Soedijarto. 2008. Landasan dan Arah Pendidikan Nasional Kita. Jakarta: Penerbit Buku Kompas.

Surakhmad, Winarno. 2009. Pendidikan Nasional-Strategi dan Tragedi. Jakarta: Penerbit Buku Kompas.

Susanto, Herri. 2014. Comunication Skills (Sukses Komunikasi, Persentasi dan Berkarier). Yogyakarta: Deepublish.

Tasmara, Toto. 2002. Membudayakan Etos Kerja Islami. Jakarta: Gema Insani.

Wansadinata, Wiratman dan G. Suprayitno. 2008. Roosseno: Jembatan dan Menjembatani. Jakarta: Yayasan Obor Indonesia.

Wiguna, Alivermana. 2014. Isu-Isu Kotemporer Pendidikan Islam. Yogyakarta : Deepublish.

Zarman, Wendi. 2012. Inilah Wasiat Nabi bagi Para Penuntut Ilmu. Jakarta: Penerbit Ruang Kata Imprint Kawan Pustaka. 